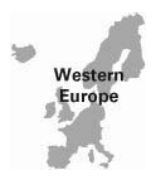

ATMOSPHERIC ENVIRONMENT

\title{
Airborne particulate matter around the Cathedral of Burgos (Castilla y León, Spain)
}

\author{
R.M. Esbert, F. Díaz-Pache, C.M. Grossi*, F.J. Alonso, J. Ordaz \\ Departamento de Geología, Universidad de Oviedo, C/Jesús Arias de Velasco S/N 33005 Oviedo, Spain \\ Received 1 July 1999; received in revised form 6 January 2000; accepted 13 January 2000
}

\begin{abstract}
A methodology to collect and analyse atmospheric particulate matter has been developed at the Cathedral of Burgos (Spain). Particles were collected in a portable particle sampler on carbon layers and stone surfaces. The analyses were undertaken under SEM-EDX by means X-ray mapping and Featurescan (a program for the automated characterisation of particles). To determine their possible sources, particles collected in the sampler and on carbon layers were classified according to their composition, mainly by cluster analysis. Then, they were compared with those deposited on stone surfaces. This classification is useful when a plan of preventive conservation for monuments is to be undertaken. In general, no important differences are observed between the chemical composition of particles directly collected from the atmosphere and those deposited on different substrates. Fine particles present the highest sulphur contents (almost $100 \%$ ), while calcium is the major element in the medium and coarse particles. Other abundant elements are silicon, chlorine and phosphorus. The number of iron-rich particles is small. The study of the material deposited on carbon layers and stone substrates has confirmed the presence of gypsum in all cases. (C) 2000 Elsevier Science Ltd. All rights reserved.
\end{abstract}

Keywords: Atmospheric particulate; Particle analysis; Stone decay; SEM/EDX; Cluster analysis

\section{Introduction}

Over recent decades an extensive research on atmospheric particles in urban environments has been carried out. Most of the papers refer to their contribution to air pollution and the effects on human health (Dzubay and Mamane, 1989; Van Borm et al., 1989, 1990; Rojas et al., 1990; Paoletti et al., 1991; Al-Rajhi et al., 1996; McMurry et al., 1996; Querol et al., 1996; BéruBé et al., 1997; Esteve et al., 1997; Harrison et al., 1997; Zou and Hooper, 1997; Kasparian et al., 1998; Chan et al., 1999; Paoletti et al., 1999, etc.). Other articles mention particulate effects on building stone decay (Haynie, 1985, 1986; Lanting, 1986; Leysen et al., 1987; Zappia et al., 1991; Hutchinson et al., 1992; Díaz-Pache et al., 1994; Nord et al., 1994; Rodríguez-Navarro and Sebastián, 1996; Esbert et al.,

\footnotetext{
* Corresponding author. Tel.: +34-98-5103384; fax: +34-985103161.

E-mail address: mgrossi@asturias.geol.uniovi.es (C.M. Grossi).
}

1996; Torfs and Van Grieken, 1997; Ausset et al., 1998, 1999; Grossi et al., 1998, etc.). This paper is focused on this last topic and presents a methodology to study solid particles in urban atmospheres.

The research has been undertaken at the Cathedral of Burgos (Castilla y León, Spain), which is one of the principal Spanish Gothic monuments, located in the city centre. The location selected for the experiment was the façade of Coronería, which is relatively sheltered from the direct action of rainfall. The stones of this façade show an intense black soiling due to particle deposition. The dominant wind directions, the situation of the main emission fixed sources and the architectural features of the façade have been taken into account to select the place for the sampling location, where airborne particles were sampled. The sampling device was placed in the most sheltered corner of this façade.

Moreover, to study the particulate matter deposited on stones, two types of substrate have also been exposed: carbon layers and stone tablets. It is well known that most particles are very difficult or almost impossible to 
discriminate from the background when deposited on stone surfaces due to the porosity and surface roughness of the stone, as well as to possible reactions with the rock material. This problem can be avoided by also exposing carbon layers glued to a glass slide. In this way, particles deposit on a plain and non-reactive surface and they can be easily identified.

The stones selected for this study were carbonate and granite rocks frequently used in Spanish buildings and monuments: Hontoria limestone (the building stone of the Burgos cathedral), Laspra dolomite (used in the Oviedo cathedral), Macael marble (used in "La Alhambra" in Granada) and Rosa Porriño granite (mainly used as an ornamental and cladding stone). In the latter case, we used granite samples with polished surface.

\section{Experimental}

\subsection{Particle sampling}

In this project, all the size ranges of the atmospheric aerosol particles (aerodynamic diameter $<0.1-1000 \mu \mathrm{m}$ ) have been studied. Particles from atmospheric aerosol and those deposited on stone surfaces have been identified. The gypsum generated by reaction between some particles and the stone has also been studied.

The following sampling methodology was carried out:

(a) Particles sampled from the atmosphere by means of a cascade impactor.

(b) Particles deposited on horizontal non-reactive surfaces (carbon layers) sheltered from rainfall.

(c) Particles deposited on stone samples placed horizontally and sheltered from rainfall.

These three methods of particle collecting were thought to be useful to know what types of atmospheric particulate matter are present in a specific environment, and which particles are most likely to deposit on reactive stone surfaces.

\section{(a) Suspended particles}

Suspended particles were collected by a three-stage cascade impactor (Microanalysis Particle Sampler model MPS-3, California Measurements Inc., Sierra Madre, CA). This small, portable sampler utilises the principle of inertial impaction to separate and collect airborne particles according to three size ranges (aerodynamic radii): $0.05-0.3,0.3-2$ and $2-35 \mu \mathrm{m}$, approximately; in this work named as "small", "medium" and "coarse", respectively. Air drawn by means of a pump is forced to circulate through the system at a constant flow rate $\left(21 \mathrm{~min}^{-1}\right)$.

The impactor stage is a stub that can be placed in the scanning electron microscope (SEM) without previous manipulation. It is covered by a layer of kapton with a small quantity of grease for optimising the separation of particles without interfering with the EDX analysis.

Thirteen sampling runs were carried out in the sampling location during a period of twelve months. Samples were collected at 11:00, 13:00 and 16:00. The duration of each sampling exercise was $7 \mathrm{~min}$. This was considered the optimum time for collecting a representative portion of most types of particles with no overlapping. However, the smallest fraction might be sometimes overloaded. The total number of taken samples was 39 , each of them consisting of three stubs containing the different size fractions.

(b) Particles deposited on carbon layers

The carbon layers had been glued onto glass slides. Particles deposit on these surfaces in a continuous way. These slides were sampled every 3 months during the 12 -month period. Samples of cumulated deposit of 6 , 9 and 12 months were also collected. To observe the particles under SEM only a coating with a carbon layer is required.

Particles deposited on this kind of surfaces are supposed to be the same as those deposited on stone surfaces but with no interferences derived from the stone nature and surface characteristics (roughness, specific surface area, etc.).

In this work, particles deposited on carbon layers are called "very coarse", because particles larger than $35 \mu \mathrm{m}$ can be deposited along with smaller ones. These very coarse particles are out of the maximum size collected by the cascade impactor. Among these particles are the big particles generated by diverse combustion processes.

\section{(c) Particles deposited on stone surfaces}

Stone was the third type of surface on which atmospheric particles were collected. As mentioned above, building or cladding carbonate and granite stones were placed in horizontal positions sheltered from rainfall. Samples were small specimens $(2 \mathrm{~cm} \times 2 \mathrm{~cm} \times 1 \mathrm{~cm})$ which can be observed using SEM without previous cutting or manipulation, only requiring carbon coating.

\subsection{Instrumental techniques}

X-ray mappings by SEM-EDX have been carried out in all the cases (particle bulk analysis). Moreover, besides SEM and EDX, a software program -Featurescan- was used when individual particles could be discriminated. Featurescan allows an automated and fast characterisation (individual particle analysis).

The electron microscope used was a JEOL 6100, with a microanalysis unit LINK eXL-100 and a silicon detector Pentafet from LINK model 6150, with an $8 \mu \mathrm{m}$ Be window. The equipment belongs to the Electron 
Microscopy Service of the Common Services of the University of Oviedo.

Taking into account the EDX technical limitations (Díaz-Pache et al., 1994) and the literature about this topic (Dzubay and Mamane, 1989; Paoletti et al., 1991; Rodríguez-Navarro and Sebastián, 1996; Torfs and Van Grieken, 1997, Harrison et al., 1997, etc.) the following elements were selected: $\mathrm{Na}, \mathrm{Mg}, \mathrm{Al}, \mathrm{Si}, \mathrm{P}, \mathrm{S}, \mathrm{Cl}, \mathrm{K}, \mathrm{Ca}, \mathrm{Ti}$, $\mathrm{V}, \mathrm{Cr}, \mathrm{Fe}, \mathrm{Ni}, \mathrm{Cu}, \mathrm{Zn}, \mathrm{Br}$ and $\mathrm{Pb}$.

Featurescan is an image analysis package that allows the automated detection, measurement and analysis of features - in our case solid atmospheric particles - of a SEM image. It can be used for chemical and morphological analysis of particles and to study the pore size of a rock. In this project Featurescan was used when individual particles could be discriminated, specifically in the case of medium and coarse particles collected by the cascade impactor and for the "very coarse" particles deposited on carbon layers. Occasionally, it was also used to count and analyse particles deposited on the polished surfaces of granite specimens, although in this case the silicon in the granite surface may interfere in the results.

When it was not possible to use Featurescan - e.g. small particles tend to form aggregates and cannot be individually analysed - only X-ray mapping by EDX was carried out in order to given chemical analysis. The program could not be used to study particle deposition on carbonate stones because their porosity and surface roughness led to images where particles could not always be correctly discriminated. Moreover, because of the higher reactivity of the substrate some particles can remain "camouflaged".

To classify and establish possible sources of particles, the data were statistically treated mainly by cluster analysis using the hierarchical method of the centroid and the non-hierarchical method of the " $\mathrm{k}$ partitions".

When considering the results, it is necessary to take into account the following limitations of the applied method and the above mentioned techniques:

- EDX detection limits: elements with atomic number smaller than sodium - e.g. nitrogen, carbon, etc. - cannot be detected. Carbonaceous particles cannot be determined; consequently it is not possible to establish the amount of soot or to analyse elemental carbon.

- When selecting grey level thresholds, that define the particles of interest, there are some difficulties in correctly fixing the particle morphological limits. So particles initially rounded, after the selection of the background, can show irregular shape. Therefore, in many cases, it is not possible to differentiate combustion aluminosilicate particles from those of silicates, such as potassium feldspars or some clays.
- Sometimes it is impossible to separate two particles when they are very close to each other. In this case, the characterisation of the aggregate is an average of the compositional characteristics of the particles involved. The morphology would be the sum of the characteristics as a group.

- Occasionally there are background points with a level of grey inside the selected interval. These points, then, are misinterpreted as particles but they are in fact surface defects.

- There will always be particles smaller than the minimum discrimination size of the selected work magnifications. Occasionally very big particles can exceed the area of analysis.

- Assuming that automotive lead is essentially present in particles smaller than $0.33 \mu \mathrm{m}$ of aerodynamic diameter, it is difficult to exclude their presence by SEM analyses. Plasma Spectroscopy Analyses (ICPS) should be required.
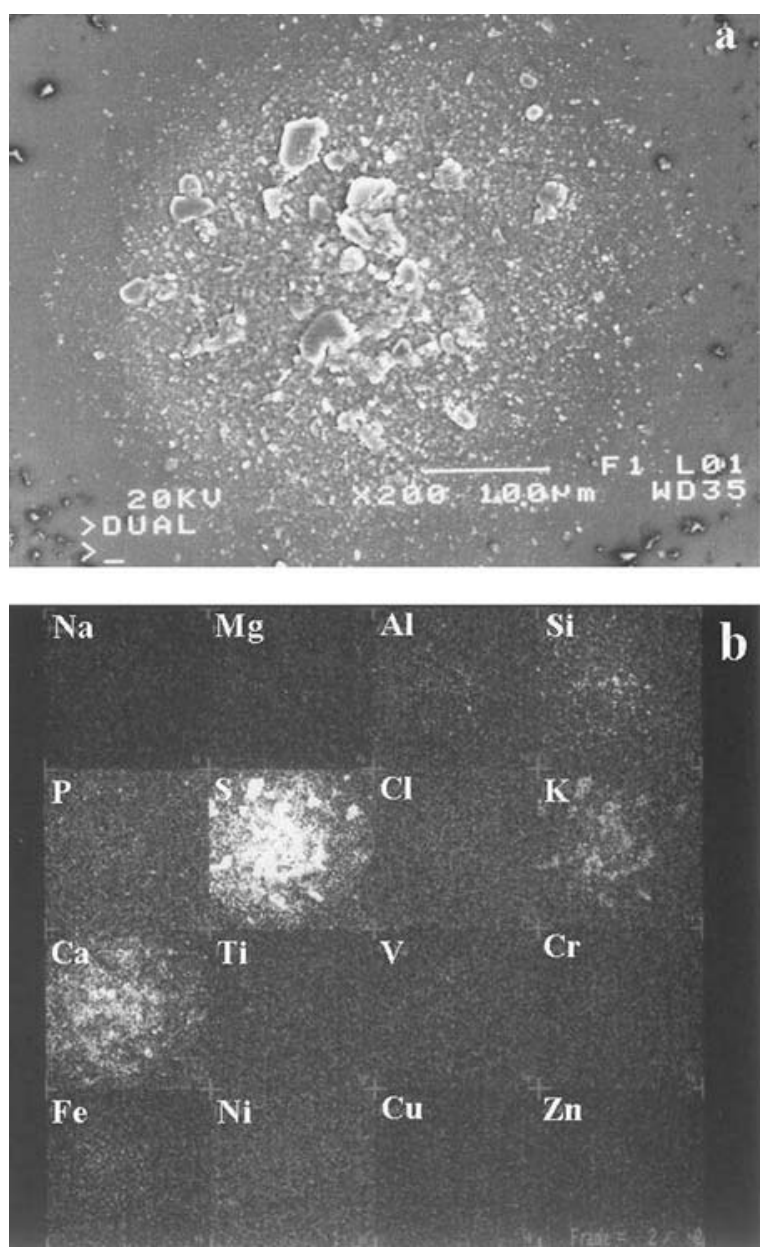

Fig. 1. Small particles collected in the impactor: (a) SEM image; (b) X-ray mapping. 


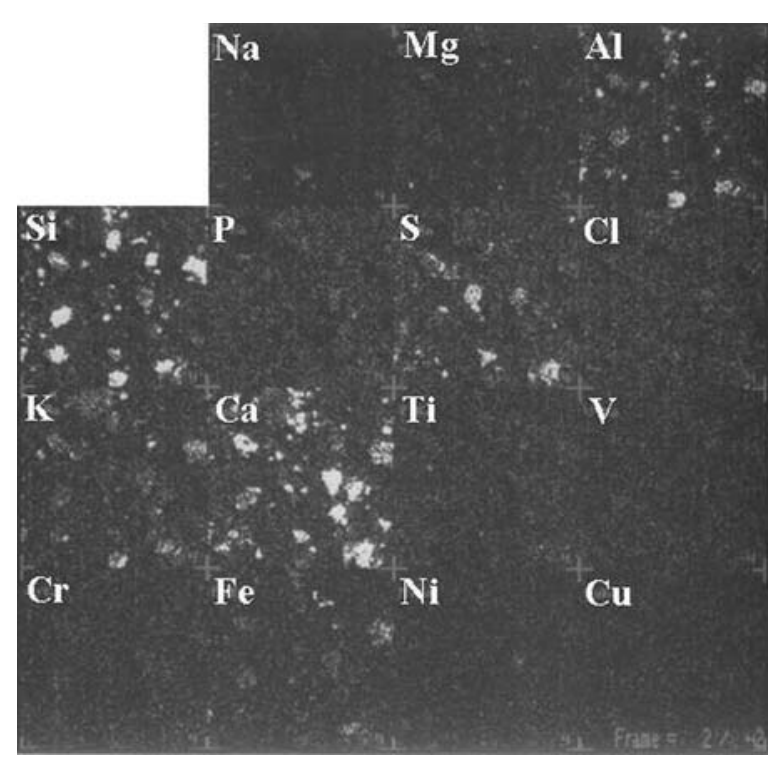

Fig. 2. Particles on carbon layer: X-ray mapping. Major elements are calcium, silicon, sulphur and aluminium.

Table 1

Percentage of marble and granite surface covered by $\mathrm{Si}, \mathrm{S}, \mathrm{Ca}$ and $\mathrm{Fe}$, calculated from $\mathrm{X}$-ray mapping and image digital processing, during exposure at the Cathedral of Burgos ${ }^{\mathrm{a}}$

\begin{tabular}{lccccc}
\hline Surface & Months & $\mathrm{Si}$ & $\mathrm{S}$ & $\mathrm{Ca}$ & $\mathrm{Fe}$ \\
\hline Marble & 0 & 0.2 & 0.3 & 100 & 0.0 \\
& 3 & 5.5 & 3.0 & 97 & 0.0 \\
& 6 & 7.1 & 10 & 94 & 0.3 \\
& 9 & 9.7 & 14 & 93 & 0.6 \\
Granite & 12 & 10 & 15 & 92 & 0.7 \\
& 0 & 99 & 0.0 & 2.9 & 7.9 \\
& 3 & 78 & 0.3 & 4.5 & 0.0 \\
& 6 & 85 & 0.5 & 5.3 & 0.0 \\
& 9 & 81 & 1.0 & 9.3 & 0.3 \\
& 12 & 57 & 7.8 & 35 & 7.4 \\
\hline
\end{tabular}

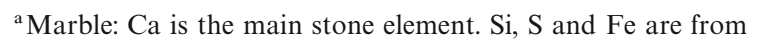
gas and particle deposition. Granite: $\mathrm{Si}$ and also $\mathrm{Ca}$ and Fe can be components of the stone. $\mathrm{S}$ is an indicator of deposition.

- Not all elements are selected for the analysis. Thus, if there is any particle rich in an excluded element, this element will not be detected and will be unnoticed.

\section{Results}

\subsection{X-ray mappings}

\subsubsection{Samples collected by the impactor}

There were notable differences in composition between the so-called small particles and the others: medium and coarse.
Small particles: these particles could not be individually identified most of the time and formed aggregates (either because their size favours ready aggregation BéruBé et al., 1997 - or because a possible overloading) composed mainly of sulphur, very often combined with potassium and occasionally with calcium (Fig. 1). In some samples, silicon and aluminium were also detected.

Medium and coarse particles: calcium, sulphur, silicon, chlorine, aluminium, phosphorus and iron were the main detected elements.

\subsubsection{Samples deposited on carbon layers}

The detected elements were mainly calcium, silicon, sulphur, aluminium, potassium, iron, and in less proportion chlorine, sodium and phosphorus. Occasionally calcium appeared associated to sulphur (gypsum) and silicon to aluminium and potassium (silicates) (Fig. 2).

\subsubsection{Samples deposited on stones}

Carbonate stones: Gypsum was observed after some period of outdoors exposure (part of the gypsum was formed by stone reaction with atmospheric $\mathrm{SO}_{2}$ and part was due to particulate matter deposition). There was as well a surface enrichment in silicon and aluminium and iron (mainly due to deposition of "soil erosion" or "dust" particles).

Granite stone: In this case the surface had an original composition formed by several silicates. After exposure, some sulphur (in the form of gypsum) was also detected. This gypsum mainly comes from gypsum air particles and fly ashes. Part of the gypsum could also come from the deposition of small particles $(<0.3 \mu \mathrm{m})$ originated by $\mathrm{SO}_{2}$ condensation and deposited on the stone by brownian movements. The amount of gypsum detected was quite higher than that we expected on a silicate surface.

Table 1 shows a quantification by image digital processing from X-ray mapping data of silicon, sulphur, calcium, and iron on marble and granite surfaces prior and after exposure. The amount of detected sulphur in the granite is notably less than that for marble. In the case of carbonate materials there is an important reaction of sulphur with the substrate. In the case of granitic materials, the source of sulphur is considered to be mainly particle deposition.

To sum up, X-ray mapping corroborated the formation or deposition of gypsum on stone surfaces, as well as the deposition of particles rich in silicon and aluminium that corresponded to the elements detected on non reactive surfaces (stubs and carbon layer). These elements seemed to come from soil erosion particles (calcite and silicates) and particles rich in sulphur. Among the latter, small particles, formed by $\mathrm{SO}_{2}$ condensation, were also included. 

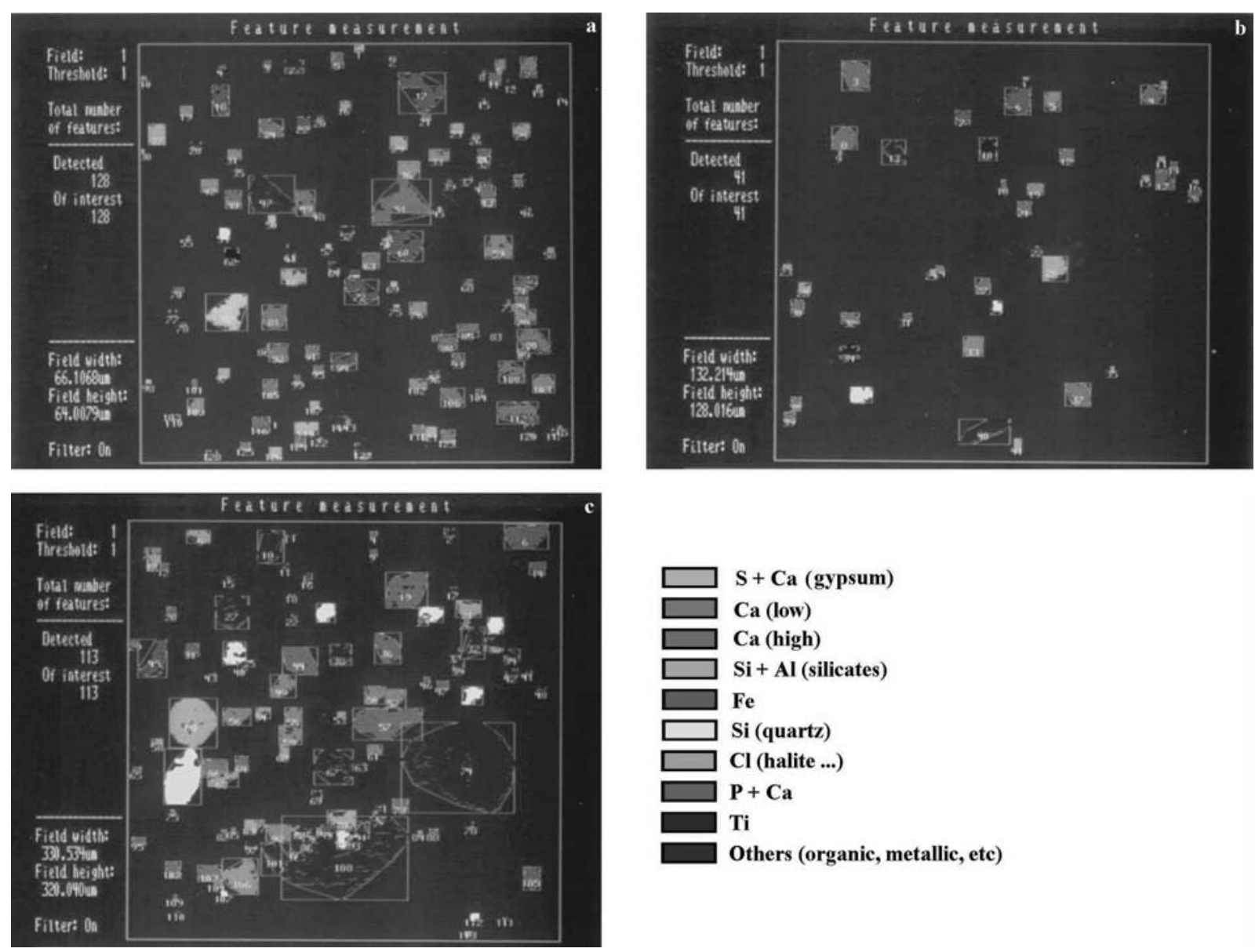

Fig. 3. Images of particles processed by Featurescan: (a) medium particles; (b) coarse particles; (c) very coarse particles.

\subsection{Automated particle analysis}

Featurescan was used to analyse particles, collected by the sampler and on surfaces, that could be individually discriminated. Reported results correspond to five sampling journeys of suspended particles during four months (November 1996 to February 1997). Analysis of particulate matter deposited on carbon layers during three months is also reported. Altogether, 1081 "medium particles", 1036 "coarse particles" and 441 "very coarse particles" were analysed.

From this data we intended to show the main particle characteristics of each group, the distribution of their elements and to determine if there are any significant differences that allow them to be classified into further groups.

\subsubsection{Size}

The first characterisation was to separate the particles of each fraction and calculate their geometric areas by means Featurescan. Fig. 3 shows several processed
Table 2

Geometric particle area $\left(\mu \mathrm{m}^{2}\right)$ of each group of particles. Data from Featurescan

\begin{tabular}{lccc}
\hline & $\begin{array}{c}\text { Medium } \\
\text { (sampler) }\end{array}$ & $\begin{array}{l}\text { Coarse } \\
\text { (sampler) }\end{array}$ & $\begin{array}{l}\text { Very coarse } \\
\text { (Carbon layer) }\end{array}$ \\
\hline Mean & 15 & 28 & 190 \\
Median & 2.5 & 9.8 & 23 \\
Mode & 0.3 & 4.1 & 6.5 \\
Minim & 0.1 & 0.7 & 1.0 \\
Maxim & 1261 & 1047 & 9662 \\
SD & 61 & 74 & 710 \\
Number & 1801 & 1036 & 441 \\
Area total & 27000 & 29000 & 83000 \\
\hline
\end{tabular}

images of the particles collected on each substrate. Table 2 shows the area average, median, mode, minimum, maximum and the standard deviation of each group. It also shows the number of analysed particles and the total area of these particles. 

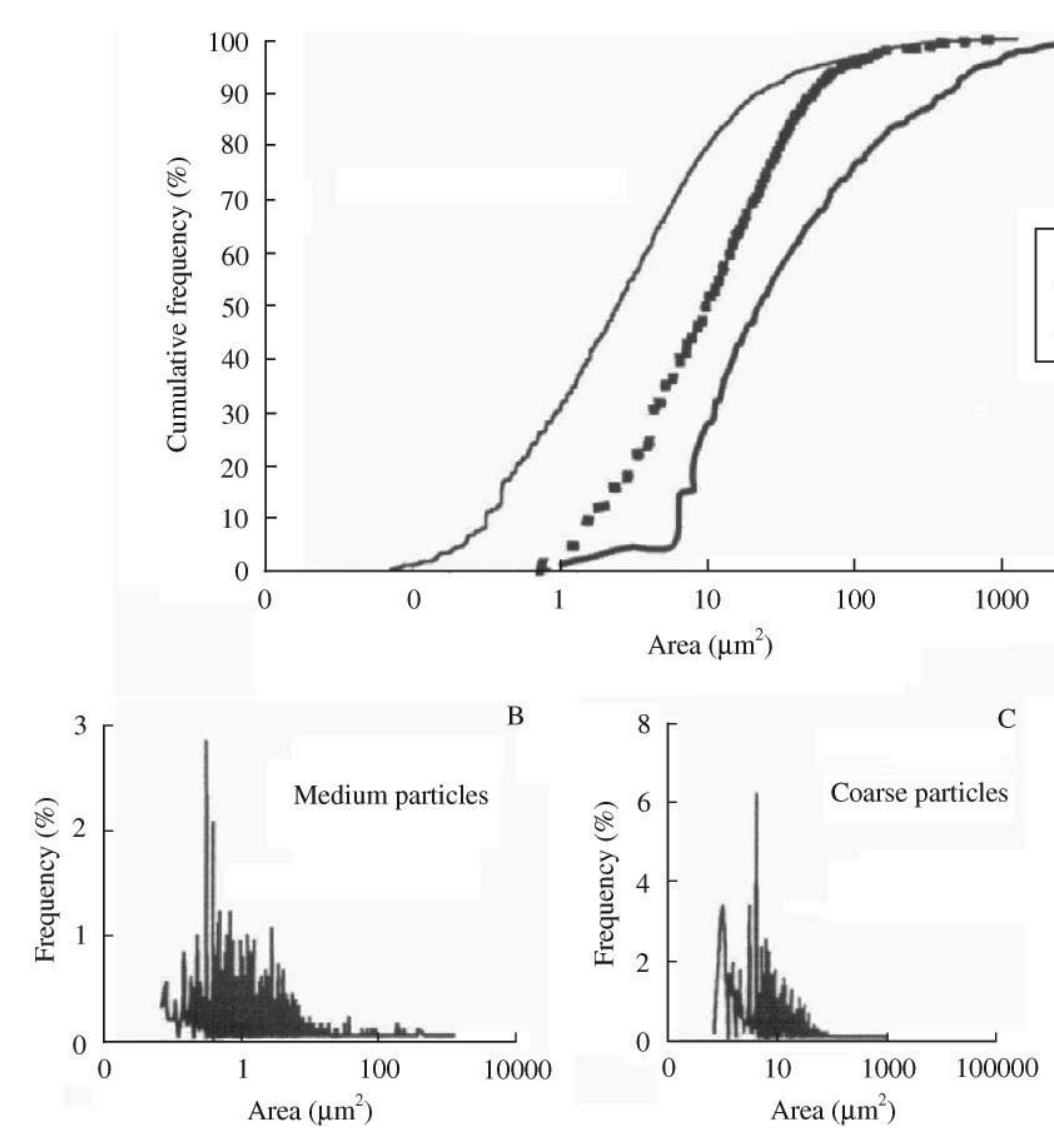

A

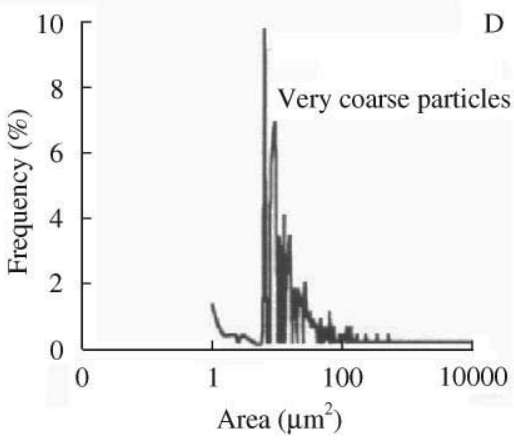

Fig. 4. Geometric particle area distribution analysed by Featurescan: (a) cumulative frequency of each group of particles; (b) relative frequency of the area of medium particles; (c) relative frequency of the area of coarse particles; (d) relative frequency of the area of very coarse particles.

Table 3

Average of the relative composition (\%) of the three groups of particle sizes. Featurescan data from EDX analysis on single particles

\begin{tabular}{lcccccccccccccccccc}
\hline Group & $\mathrm{Na}$ & $\mathrm{Mg}$ & $\mathrm{Al}$ & \multicolumn{1}{c}{$\mathrm{Si}$} & $\mathrm{P}$ & $\mathrm{S}$ & $\mathrm{Cl}$ & $\mathrm{K}$ & $\mathrm{Ca}$ & $\mathrm{Ti}$ & $\mathrm{V}$ & $\mathrm{Cr}$ & $\mathrm{Fe}$ & $\mathrm{Ni}$ & $\mathrm{Cu}$ & $\mathrm{Zn}$ & $\mathrm{Br}$ & $\mathrm{Pb}$ \\
\hline Medium & 3.1 & 2.8 & 5.1 & 8.9 & 7.5 & 11.0 & 10.8 & 5.7 & 21.7 & 4.3 & 3.6 & 3.2 & 3.8 & 2.1 & 3.3 & 1.7 & 0.7 & 1.0 \\
Coarse & 2.9 & 2.7 & 5.3 & 10.2 & 8.0 & 8.8 & 13.2 & 5.5 & 22.6 & 3.7 & 3.1 & 2.7 & 3.7 & 1.9 & 2.1 & 1.5 & 0.6 & 0.8 \\
Very coarse & 1.0 & 2.2 & 5.4 & 16.4 & 4.6 & 11.6 & 4.6 & 5.4 & 32.1 & 2.8 & 2.3 & 2.1 & 3.8 & 1.5 & 1.3 & 1.2 & 0.6 & 0.8 \\
\hline
\end{tabular}

There was a size gradation from medium to very coarse particles, as it could be seen from the data. However, anomalous cases could be observed in each group (Fig. 4).

\subsubsection{Composition}

Once sizes were established, medium, coarse and very coarse particles were compared according to their composition. To do that, the average of each selected element percentage was calculated on each group of particles (Table 3). Small particles were not considered here because they could not be individually analysed.
Calcium was the predominant element in all the cases. Other elements that had high percentages were sulphur, silicon, chlorine and phosphorus. The group of very coarse particles presented higher percentages of calcium and silicon and lower percentages of chlorine and phosphorus than the other groups.

Average values of element percentages were analysed to determine if there are any significant differences among them. Using the tests of Krustall-Wallis (nonparametric one way ANOVA, critical level $\alpha=0.05$ ) and 

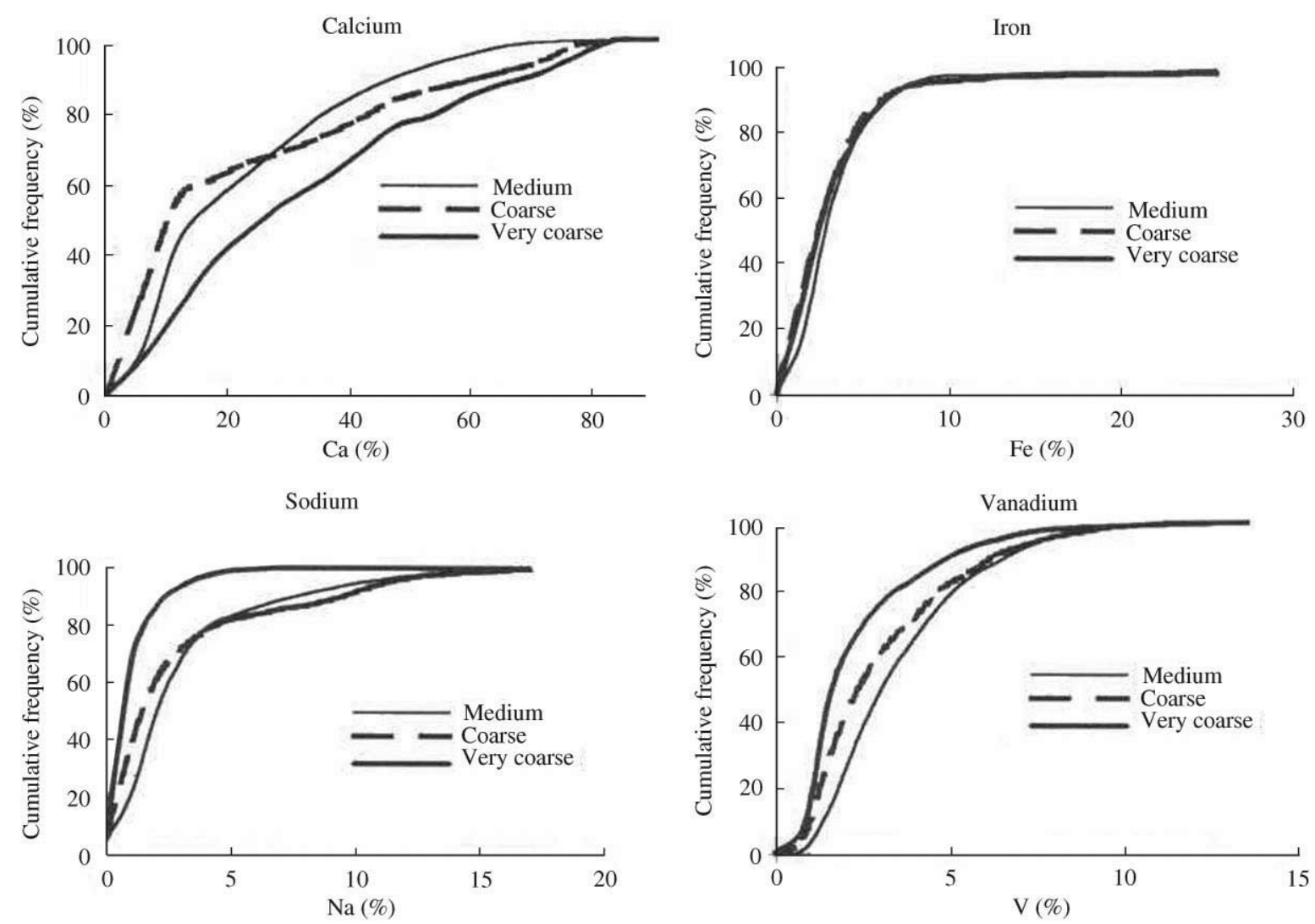

Fig. 5. Cumulative frequency distributions of the percentages of some selected elements in each group of particles.

Table 4

Medium size particle group. Centres of the five clusters (non-hierarchical method) selected from hierarchical method. Standardised values of the relative concentration of the element in the particle. Successive cluster analysis was carried out on clusters 1 and 5 (see Table 5)

\begin{tabular}{lrrrrrrrrrrrrrrrrrrrrrrrrrrrrrr}
\hline Cluster & $\mathrm{Na}$ & $\mathrm{Mg}$ & $\mathrm{Al}$ & $\mathrm{Si}$ & $\mathrm{P}$ & $\mathrm{S}$ & $\mathrm{Cl}$ & $\mathrm{K}$ & $\mathrm{Ca}$ & $\mathrm{Ti}$ & $\mathrm{V}$ & $\mathrm{Cr}$ & $\mathrm{Fe}$ & $\mathrm{Ni}$ & $\mathrm{Zn}$ & $\mathrm{Br}$ & $\mathrm{Pb}$ \\
\hline 1 & -0.14 & 0.39 & 0.12 & 0.00 & 0.35 & -0.07 & -0.13 & 0.61 & -0.64 & 0.61 & 0.61 & 0.74 & 0.05 & 0.67 & 0.50 & 0.32 & 0.48 \\
2 & -0.68 & -0.69 & $\mathbf{1 6}$ & -0.74 & -0.99 & -1.1 & -0.77 & -0.82 & -1.1 & -0.98 & -0.98 & -1.0 & -0.51 & -1.1 & -0.62 & -0.72 & -1.0 \\
3 & -0.54 & -0.41 & -0.03 & -0.05 & -0.33 & -0.69 & -0.60 & -0.77 & -0.44 & $\mathbf{9 . 3}$ & $\mathbf{1 . 2}$ & -0.24 & -0.13 & -0.38 & -0.25 & 0.04 & -0.36 \\
4 & -0.42 & -0.46 & -0.32 & -0.33 & -0.56 & -0.49 & -0.47 & -0.68 & -0.53 & -0.44 & -0.60 & -0.53 & $\mathbf{7 . 0}$ & -0.56 & -0.34 & 0.17 & -0.22 \\
5 & 0.12 & -0.29 & -0.12 & 0.01 & -0.26 & 0.07 & 0.12 & -0.45 & 0.52 & -0.51 & -0.56 & -0.56 & -0.23 & -0.50 & -0.38 & -0.25 & -0.37 \\
\hline
\end{tabular}

Mann-Whitney (test to compare two continuos independent variables) it was observed that the differences in the average values of the most abundant elements $(\mathrm{Si}, \mathrm{P}, \mathrm{S}, \mathrm{Cl}$ and $\mathrm{Ca}$ ) were significant in all the cases. $\mathrm{Na}, \mathrm{Mg}, \mathrm{Ti}, \mathrm{V}$, $\mathrm{Cr}, \mathrm{Cu}$ and $\mathrm{Zn}$ also presented significant differences in all the cases, being the highest values in the medium particle group. Finally, $\mathrm{Al}, \mathrm{K}, \mathrm{Fe}, \mathrm{Br}$ and $\mathrm{Pb}$ did not show significant differences between the groups of coarse and very coarse particles. Fig. 5 shows the distributions of some of the selected elements: $\mathrm{Na}, \mathrm{Ca}, \mathrm{V}$ and Fe.

\subsubsection{Classification}

Particle classification was carried out by cluster analysis, using as variables the standardised values ${ }^{1}$ of the elements. Firstly, hierarchical methods (centroid method,

\footnotetext{
${ }^{1}$ Standardised values $z=(x-\mu) / \sigma$, where $x$ is the relative concentration (\%) of the element in the particle, $\mu$ the mean of the relative concentration $(\%)$ of the element in the group of fraction of particles (medium, coarse or very coarse) and $\sigma$ the standard deviation.
} 
Table 5

Clusters obtained in the medium size particle group from the primary five cluster and after successive clustering of clusters 1 and 5

\begin{tabular}{|c|c|c|c|c|}
\hline Cluster & $\begin{array}{l}\text { Main cluster element } \\
\text { Relative average } \\
\text { composition }(\%)\end{array}$ & Number of particles & $\begin{array}{l}\text { Number of X-ray } \\
\text { counts (average) }\end{array}$ & Assigned type \\
\hline \multirow[t]{3}{*}{1} & None & 775 & 449 & 1. Organic $^{\mathrm{a}}$ \\
\hline & None & 773 & 448 & a: organic \\
\hline & Cl: 24; Zn: 14; S: 12 & 2 & 885 & b: chlorine and zinc (no organic) \\
\hline 2 & Al: 70 & 2 & 906 & 2. Rich in aluminium \\
\hline 3 & $T i: 31 ; V: 6$ & 5 & 705 & 3. Rich in titanium and vanadium \\
\hline 4 & $\mathrm{Fe}: 38$ & 27 & 967 & 4. Rich in iron \\
\hline \multirow[t]{13}{*}{5} & Ca: 31 & 992 & 899 & 5. Rich in crustal elements ${ }^{\mathrm{b}}$ \\
\hline & Ca: 56 & 215 & 915 & a: very rich in calcium (calcite) \\
\hline & Ca: 33 & 220 & 842 & b: rich in calcium \\
\hline & Ca: 38; P: 31 & 45 & 828 & c: calcium and phosphorous \\
\hline & Ca: 29; S: 26 & 201 & 991 & d: calcium and sulphur (gypsum) \\
\hline & $\mathrm{Cl}: 46$; $\mathrm{Na}: 9$ & 120 & 874 & e: sodium chloride \\
\hline & Si: 53 & 23 & 914 & f: silicon (quartz) \\
\hline & Si: $20 ; \mathrm{Al}: 10 ; \mathrm{Ca}: 13$ & & & \\
\hline & $\begin{array}{l}\text { K: 6; Na: J; Fe: } 5 \\
\text { Si:26; Ca:21 }\end{array}$ & 155 & 860 & $\begin{array}{l}\text { g: s1licates } \\
\text { g1. with calcium }\end{array}$ \\
\hline & Si:20; Cl:20 & & & g2. with chlorine \\
\hline & $\mathrm{Cl}: 17 ; \mathrm{S}: 14$ & & & g3. with chlorine and sulphur (mix) \\
\hline & Si:29; Al: 15 & & & g4. with aluminium \\
\hline & $\mathrm{Na}: 19$ & 13 & 661 & h: rich in sodium (probably nitrates) \\
\hline
\end{tabular}

${ }^{a}$ Cluster 1 - Considered mainly organic particles because no predominant element was detected and the low number of the particle $\mathrm{X}$-ray counts.

${ }^{\mathrm{b}}$ Cluster 5 - Considered rich in crustal elements because of the abundance of calcium. Also sulphur-, chlorine- and sodium-rich particles were included in this cluster.

being the measure of similarity the squared Euclidean distance) were used to determine the number of clusters. Then, non-hierarchical methods were used to determine the characteristics and the number of particles of each cluster (method of K partitions: "quick cluster of SPSS"). Finally, once the clusters were established, the relative average percentage of the studied elements of each cluster was estimated.

Once the primary clusters were established, this methodology was successively repeated in the cases where groups of particles were not well defined until it was considered that most of particles were correctly classified. The case of medium particles is presented as an example. Five clusters were firstly selected from hierarchical cluster analysis. Table 4 shows the chemical characteristics of these five selected clusters using non-hierarchical methods. The most significant elements to characterise the cluster are outlined. In Table 5 each cluster is given a name according to the most characteristic element and related to the type of particle. This table shows, as well, the final result after successively applying cluster methods.

Using these procedures and data from the specific literature (Dzubay and Mamane, 1989; Van Borm et al.,
1989, 1990; Rojas et al., 1990; Clarke, 1992; Torfs and Van Grieken, 1997; Harrison et al., 1997; Zou and Hooper, 1997, etc.) a particle classification was reached and it is shown in Table 6.

\subsection{Particles on stone substrates}

Several types of particles were collected on the stone materials exposed at Burgos Cathedral. Among them, fly ashes from oil based fuels combustion (Fig. 6a) composed of mainly sulphur and also calcium and some vanadium were observed. Also, particles of biological origin were seen (Fig. 6b) and soil erosion particles. There are, as well, rounded particles of iron and of silicon-aluminium (bigger than those of iron) both probably generated by coal combustion (Figs. 6c and d) and finally, titaniumrich particles.

These types of particles are similar to those observed on carbon layers (very coarse group). However, all the particles, with exception of the big sulphur fly ashes, are present in all the types of deposits, both those collected by the sampler or deposited on carbon layers.

It is worth to point out the role of very fine particles in the generation of decay products on stone surfaces. These 
Table 6

Classification of particles from each of the three studied groups $(\%)$

\begin{tabular}{|c|c|c|c|}
\hline & Medium & Coarse & Very coarse \\
\hline Organic & 43 & 43 & 26 \\
\hline Soil erosion: & 29 & 27 & 46 \\
\hline Calcite $(\mathrm{Ca})$ & 12 & 14 & 21 \\
\hline Quartz (Si) & 1.0 & 2.6 & 5.2 \\
\hline Silicates ( $\mathrm{Si}, \mathrm{Al}, \mathrm{K}, \mathrm{Fe})$ & 3.9 & 1.9 & 6.4 \\
\hline $\mathrm{Rich}$ in $\mathrm{Ca}$ & 12 & 8.1 & 13 \\
\hline Rich in sulphur: & 11 & 3.6 & 15 \\
\hline Calcium sulphate $(\mathrm{S}, \mathrm{Ca})$ & 11 & 2.7 & $13^{\mathrm{a}}$ \\
\hline Sodium sulphate $(\mathrm{S}, \mathrm{Na})$ & - & 0.5 & - \\
\hline Potassium sulphate $(\mathrm{S}, \mathrm{K})$ & - & 0.4 & - \\
\hline Fly ashes (S) & - & - & 2 \\
\hline Rich in chlorine: & 8.8 & 12 & 0.0 \\
\hline Sodium chloride $(\mathrm{Cl}, \mathrm{Na})$ & 6.6 & 9.1 & - \\
\hline Chlorides $(\mathrm{Na}, \mathrm{K}, \mathrm{Ca}, \mathrm{S} \ldots)$ & 2.2 & 2.6 & - \\
\hline Rich in silicon and aluminium & 2.8 & 5.2 & 9.5 \\
\hline Rich in iron: & 1.5 & 1.5 & 1.4 \\
\hline Iron $(\mathrm{Fe})$ & 1.5 & 1.1 & 1.4 \\
\hline Iron and nickel $(\mathrm{Fe}, \mathrm{Ni})$ & - & 0.1 & - \\
\hline Iron and chromium $(\mathrm{Fe}, \mathrm{Cr})$ & - & 0.3 & - \\
\hline Rich in calcium and phosphorus & 2.5 & 7.0 & 0.0 \\
\hline Others: & 1.2 & 1.1 & 2.5 \\
\hline Aluminium (Al) & 0.1 & 0.8 & 0.2 \\
\hline Titanium and vanadium $(\mathrm{V})$ & 0.3 & 0.1 & 0.2 \\
\hline Chloride and zinc $(\mathrm{Cl}, \mathrm{Zn})$ & 0.1 & - & - \\
\hline Sodium $(\mathrm{Na})$ & 0.7 & - & - \\
\hline Potassium (K) & - & 0.2 & - \\
\hline Phosphorus (P) & - & - & 1.4 \\
\hline Calcium and bromine $(\mathrm{Ca}, \mathrm{Br})$ & - & - & 0.2 \\
\hline Calcium and different metals & - & - & 0.5 \\
\hline
\end{tabular}

${ }^{\text {a }}$ Particles classified as gypsum could be fly ashes, which have the same composition (high $\mathrm{Ca}$ and $\mathrm{S}$ contents). Numbers in italic: total (sum) percentage of each type of particles.

particles are composed almost only by sulphur. The amount of sulphur, sometimes combined with potassium and occasionally with calcium (probably condensation sulphates) outlines the importance of atmospheric $\mathrm{SO}_{2}$ in carbonate stone decay. As it is well known, this gas will be absorbed, to a greater or lesser extent, by the stone depending on the amount of carbonate, porosity, specific surface and surface roughness. The action of $\mathrm{SO}_{2}$ can also be important on granitic rocks because it can react with calcite particles and deposit on the stone surface as calcium sulphate (Van Borm et al., 1989).

\section{Discussion}

Taking into account the data obtained from the chemical analysis and treatment and its subsequent statistical processing, it is possible to make some observations:

Organic particles: Particles in which none of the selected elements is predominant. That is due to the fact that their main elements $(\mathrm{H}, \mathrm{C}, \mathrm{N}, \mathrm{O})$ cannot be detected by EDX. A thin-window $\mathrm{Si}(\mathrm{Li})$ would be necessary for the detection of these low-Z elements. Moreover, these particles presented a low number of X-ray counts in the EDX analysis. Most of these particles probably have a biological origin. Some might also be carbon-based particles from diesel exhausts (Zou and Hooper, 1997). They are the most abundant particles in the medium and coarse fractions and very abundant in the very coarse fraction. Their abundance in the medium and coarse groups explains the relatively high percentages of metallic elements in these fractions.

Calcium- and silicon-rich particles: The abundance of calcium in all the groups (fractions of particles) is probably because particles were collected outside the façade of Coronería, built with a very pure limestone which is now highly deteriorated (Alonso et al., 1994). The highest percentage of these particles was found on the "very coarse" group due to their deposition by gravitational settling. With respect to quartz and other silicate particles, the highest percentage also appeared in the "very coarse" group. Both types of particles are originated by soil erosion.

Sulphur-rich particles: The percentage of sulphur and sulphur-rich particles decreases from the small to the coarse. The finest particles $(<0.1 \mu \mathrm{m})$ are formed by homogeneous or heterogeneous condensation of atmospheric $\mathrm{SO}_{2}$ from fossil fuels combustion (Van Borm et al., 1989; Clarke, 1992). The percentage of this type of particles increases again in the "very coarse" group, mainly due to the presence of big fly ashes from fossil fuels combustion, which cannot be collected by the sampler. Gypsum particles can be found in all the groups in a significant percentage. It is possible (see Table 6) that at least $3 \%$ of all the particles in each fraction come from the removal of gypsum from the crusts of the Cathedral walls.

Chlorine-rich particles: This type of particles is present almost only in the medium and coarse group. Chlorine usually combines with sodium. The lack of chlorine-rich particles in the "very coarse" fraction could be explained by the high hygroscopicity of chlorine salts $(\mathrm{NaCl}$ in this case). These particles deposited on the carbon layers could be dissolved under Burgos environmental conditions (HR $>70 \%$ during the experiment time). The same processes take place with many nitrates. On stone substrates, these dissolved salts can migrate within the stone and may cause stone decay when crystallising. They probably derived from de-icing salts because they were mainly sampled in the runs of November, December and February, with 12, 12 and 15 days of minimum temperature under $0^{\circ} \mathrm{C}$, respectively.

Silicon- and aluminium-rich particles: The composition of these particles is similar to some soil erosion or dust particles, but their shape is rounded. They are interpreted as derived from coal combustion. 

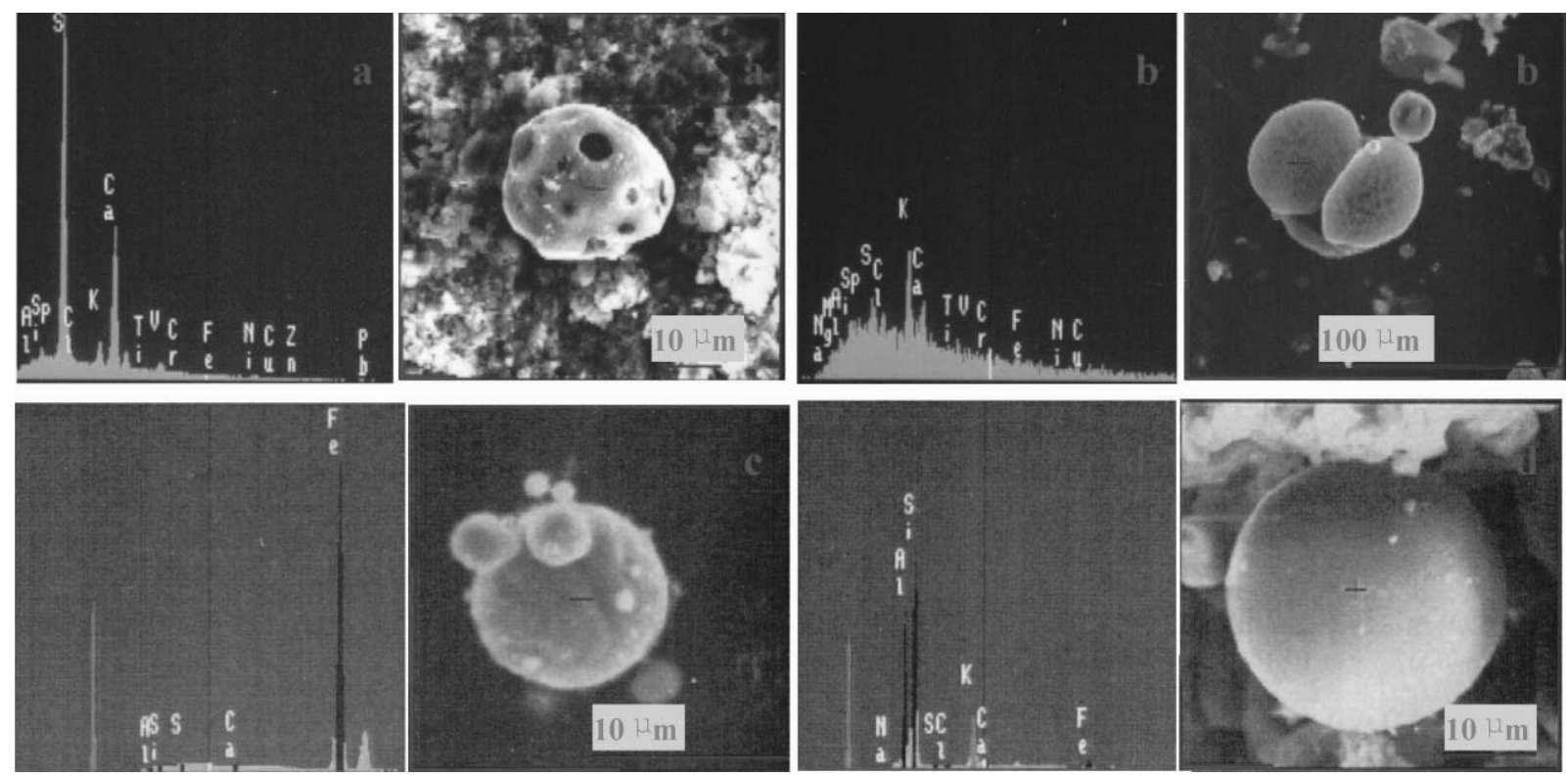

Fig. 6. X-ray analysis and images of some particles deposited on stone surfaces: (a) fly ash from combustion of oil based fuels; (b) particle of organic nature, possibly pollen; (c) iron particle probably from coal combustion; (d) aluminosilicate (silicon and aluminium) particle from coal combustion.

Iron-rich particles: They are generally rounded and probably come from the combustion of fossil fuels. There are some that are not rounded (only a few) derived mainly from other industrial activities and/or soil erosion.

Calcium- and phosphorus-rich particles: They are only present in the coarse and medium fractions. Particles rich in phosphorus and silicon can occasionally be found in the very coarse group. Their source is uncertain but they could be derived from incinerator plants, manufacturing or use of fertilisers and/or bird excrements.

Others: Other particles, less abundant and from different sources, were also observed; for instance, aluminium-rich particles from the erosion of aluminium compounds, sodium-rich particles (probably nitrates), etc.

\section{Conclusions}

A methodology combining particle collection and SEM analysis was used to characterise airborne particulate matter around the Cathedral of Burgos (Castilla y León, Spain). This methodology uses several procedures to collect particles (impact sampler, carbon layers and stone substrates). The combined use of techniques of observation (SEM) and microanalysis (EDX), together with an automated program of image analysis and the further multivariate data analysis, also constitutes a method valid to the characterisation of these atmospheric particles. Nevertheless, some limitations have to be taken into account. These can be EDX analysis limitations, i.e. no carbon or nitrogen detection, or derived from the difficulty to discriminate particles which impedes their automated analysis.

In general, no important differences are observed between the chemical composition of particles directly collected from the air and those deposited on different substrates. Small particles present the highest sulphur contents (almost $100 \%$ ) and come from the condensation of atmospheric $\mathrm{SO}_{2}$ generated by different combustion processes. Most of the medium, coarse and very coarse particles are soil erosion particles from earth materials and organic particles. Calcium is the major element in these groups of particles. Other abundant elements are sulphur, silicon, chlorine and phosphorus. Chlorine is almost only present in medium and coarse particles. The number of metallic particles from industrial sources is scarce. Also, the number of rounded iron-rich particles is small, probably indicating a low contribution of particles derived from coal combustion. On the whole, no particles with high percentages of lead or bromine, which are characteristic of petrol, were observed. This leads to the conclusion that most of the analysed combustion particles derived from other oil-based products. The amount of sulphur-rich particles decreases as particle size increases, but the presence of sulphur increases in the very coarse fraction due to the deposit of big fly ashes.

The study of the material deposited on carbon layers and stone substrates has confirmed the presence of 
gypsum in all cases. This gypsum can be attributed to gas and particle reaction with the substrate, to reaction between particles with no substrate participation or to the deposit of gypsum from erosion. In the case of carbonate materials all these sources are present, although the most important mechanism is the reaction with the substrate. In the case of granitic materials, the reaction with the substrate is considered to be almost negligible and the total amount of detected gypsum is then notably less than that for carbonate substrates.

The most stone-damaging particles of those studied in this work are the smallest ones. Due to their chemical composition, high specific surface area and way of deposit, they are very likely to react with the stones, especially in the case of those of carbonate nature. Besides, being more reactive they can also maintain the humidity of the stone and facilitate the uptake of further pollutants. On the other hand, big sulphur fly ashes can act as nuclei for the formation of gypsum. The role of other reactive or catalytic particles could not be assessed either because they could not be sampled, identified or analysed due to method limitations or merely because they were not present in the air.

\section{Acknowledgements}

The authors wish to acknowledge the financial support of this research to CICYT (project CC95-SEC0501), FICYT (project PB-REC96-98), "Junta de Castilla y León" (contract CN 95-028B1) and "Fundación Caja de Madrid". The authors wish to thank also to Dr Norberto Corral from the University of Oviedo for revising the statistical analysis, to Mrs. Sarah Smart and Mr. Barry J. Hunt from STATS Consultancy (St. Albans - UK) and Mr. Richard Tews for revising the English text and to Dr. Alfredo Quintana from the Electronic Microscopy Service of the University of Oviedo for his help in the use of the SEM.

\section{References}

Alonso, F.J., Díaz-Pache, F., Esbert, R.M., 1994. Stone-environment interaction, first part: alteration forms developed on the stone of Burgos Cathedral. Informes de la Construcción 46, 5-18.

Al-Rajhi, M.A., Al-Shayeb, S.M., Seaward, M.R.D., Edwards, H.G.M., 1996. Particle size effect for metal pollution analysis of atmospherically deposited dust. Atmospheric Environment 30, 145-153.

Ausset, P., Bannery, F., Del Monte, M., Lefèvre, R.A., 1998. Recording of pre-industrial atmospheric environment by ancient crusts on stone monuments. Atmospheric Environment 32, 2859-2863.
Ausset, P., Del Monte, M., Lefèvre, R.A., 1999. Embryonic sulphated black crusts on carbonate rocks in atmospheric simulation chamber and in the field: role of carbonaceous fly-ash. Atmospheric Environment 33, $1525-1534$.

BéruBé, K.A., Jones, T.P., Williamson, B.J., 1997. Electron microscopy of urban airborne particulate matter. European Microscopy and Analysis 9-11.

Chan, Y.C., Simpson, R.W., Mctainsh, G.H., Vowles, P.D., Cohen, D.D., Bailey, G.M., 1999. Source apportionment of $\mathrm{PM}_{2.5}$ and $\mathrm{PM}_{10}$ aerosols in Brisbane (Australia) by receptor modelling. Atmospheric Environment 33, 3251-3268.

Clarke, A.G., 1992. The atmosphere. In: Understanding our Environment. The Royal Society of Chemistry, London, pp. 5-51.

Díaz-Pache, F., Alonso, F.J., Esbert, R.M., 1994. La microscopía electrónica de barrido aplicada al estudio de partículas sólidas de contaminación depositadas sobre la piedra monumental. Ingeniería Civil 101, 29-36.

Dzubay, T.G., Mamane, Y., 1989. Use of electron microscopy data in receptor models. Atmospheric Environment 23, 467-476.

Esbert, R.M., Díaz-Pache, F., Alonso, F.J., Ordaz, J. Grossi, C.M., 1996. Solid particles of atmospheric pollution found on the Hontoria Limestone of Burgos Cathedral (Spain). In: Proceedings of the 8th International Congress on Deterioration and Conservation of Stone, pp. 393-399. Möller Druck und Verlag Gmbh, Berlin.

Esteve, V., Rius, J., Ochando, L.E., Amigó, J.M., 1997. Quantitative $\mathrm{X}$-ray diffraction phase analysis of coarse airborne particulate collected by cascade impactor sampling. Atmospheric Environment 31, 3963-3967.

Grossi, C.M., Esbert, R.M., Díaz-Pache, F., 1998. Decay and durability of building stones in urban environments. Materiales de Construcción 48 (252), 5-25.

Harrison, R.M., Smith, D.J.T., Pio, C.A., Castro, L.M., 1997. Comparative receptor modelling study of airborne particulate pollutants in Birmingham (United Kingdom), Coimbra (Portugal) and Lahore (Pakistan). Atmospheric Environment 31, 3309-3321.

Haynie, F.H., 1985. Size distribution of particles that may contribute to soiling of material surfaces. Journal Air Pollution Control Association 35, 552-554.

Haynie, F.H., 1986. Theoretical model of soiling of surfaces by airborne particles. In: Aerosols. Lewis, Chelsea, Michigan, pp. 951-959.

Hutchinson, A.J., Johnson, J.B., Thompson, G.E., Wood, G.C., 1992. The role of fly-ash particulate material and oxide catalysts in stone degradation. Atmospheric Environment 26A, 2795-2803.

Kasparian, J., Frejafon, E., Rambaldi, P., Yu, J., Vezin, B., Weolf, J.P., Ritter, P., Viscardi, P., 1998. Characterization of urban aerosols using SEM-microscopy, X-ray analysis and Lidar measurements. Atmospheric Environment 32, 2957-2967.

Lanting, R.W., 1986. Black smoke and soiling. In: Aerosols. Lewis, Publishers, USA, pp. 923-932.

Leysen, L.A., Roekens, E.J., Storms, H., Van Grieken, R.E., 1987. Classification of suspended particles in deposition samples and run-off water samples from a limestone cathedral. Atmospheric Environment 21, 2425-2433. 
McMurry, P.H., Litchy, M., Huang, P., Xiaoping, C., Turpin, B.J., Dick, W.D., Hanson, A., 1996. Elemental composition and morphology of individual particles separated by size and hygroscopicity with the TDMA. Atmospheric Environment 30, 101-108.

Nord, A.G., Svärdh, A., Tronner, K., 1994. Air pollution levels reflected in deposits on building stone. Atmospheric Environment 28, 2615-2622.

Paoletti, L., Diociauti, M., Falchi, M., Pisant, D., Ziemacki, G., 1991. Quantitative analysis of airborne breathable particles. A comparison between different analytical techniques. Atmospheric Environment 25, 237-242.

Paoletti, L., Diociaiuti, M., De Beradis, B., Santucci, S., Lozzi, L., Picozzi, P., 1999. Characterisation of aerosol individual particles in a controlled underground area. Atmospheric Environment 33, 3603-3611.

Querol, X., Alastuey, A., López-Soler, A., Mantilla, E., Plana, F., 1996. Mineral composition of atmospheric particulates around a large coal-fired power station. Atmospheric Environment 30, 3557-3572.

Rodríguez-Navarro, C., Sebastián, E., 1996. Role of particulate matter from vehicle exhausts on porous building stone (limestone) sulfation. The Science of the Total Environment 187, 79-91.

Rojas, C.M., Artaxo, P., Van Grieken, R., 1990. Aerosols in Santiago de Chile: a study using receptor modeling with $\mathrm{X}$-ray fluorescence and single particle analysis. Atmospheric Environment 24b, 227-241.

Torfs, K., Van Grieken, R., 1997. Chemical relations between atmospheric aerosols deposition and stone decay layers on historic buildings at the Mediterranean coast. Atmospheric Environment 31, 2179-2192.

Van Borm, W.A., Adams, F.C., Maenhaut, W., 1989. Characterization of individual particles in the Antwerp aerosol. Atmospheric Environment 23, 1139-1151.

Van Borm, W.A., Adams, F.C., Maenhaut, W., 1990. Receptor modeling of the Antwerp aerosol. Atmospheric Environment 24b, 419-435.

Zappia, G., Sabbioni, C., Gobbi, C., 1991. Carbonaceous aerosol on marble and limestone monuments. Journal of Aerosol Science 22 (1), S581-S584.

Zou, L.Y., Hooper, M.A., 1997. Size-resolved airborne particles and their morphology in central Jakarta. Atmospheric Environment 31, 1167-1172. 